OPEN ACCESS

Edited by:

Juliano Bordignon,

Fundação Oswaldo Cruz (Fiocruz),

Brazil

Reviewed by:

Venkataramana M.,

DRDO-BU-CLS, India

Chang Li,

Academy of Military Medical

Sciences (AMMS), China

Min Zheng,

Guangxi University, China

Fen Ge Yin,

Yunnan Agricultural University, China

*Correspondence:

Mingxiao Ma

Injzmmx@163.com

Specialty section:

This article was submitted to

Virology,

a section of the journal

Frontiers in Microbiology

Received: 16 April 2018

Accepted: 19 July 2018

Published: 03 August 2018

Citation:

Sun L, Li M, Fei D, Diao Q, Wang J,

Li L and Ma M (2018) Preparation and Application of Egg Yolk

Antibodies Against Chinese Sacbrood

Virus Infection.

Front. Microbiol. 9:1814.

doi: 10.3389/fmicb.2018.01814

\section{Preparation and Application of Egg Yolk Antibodies Against Chinese Sacbrood Virus Infection}

\author{
Li Sun ${ }^{1}$, Ming $L^{1}{ }^{1}$, Dongliang Fei ${ }^{1}$, Qingyun Diao ${ }^{2}$, Jian Wang ${ }^{3}$, Liqin $L i^{3}$ and \\ Mingxiao $\mathrm{Ma}^{1 *}$
}

${ }^{1}$ Institute of Biological Sciences, Jinzhou Medical University, Jinzhou, China, ${ }^{2}$ Honeybee Research Institute, Chinese Academy of Agricultural Sciences, Beijing, China, ${ }^{3}$ Tianjin Speerise Challenge Biotechnology Co., Ltd., Tianjin, China

Chinese sacbrood virus (CSBV) infects Apis cerana larvae, resulting in the inability of the larvae to pupate and their consequent death, which may pose a serious threat to entire colonies. As there is no effective medical treatment for CSBV infections, further studies are necessary. In this study, an effective treatment for CSBV is described, based on a specific immunoglobulin $Y(\lg Y)$ from egg yolk against CSBV. The inactivated vaccine was produced by ultracentrifugation and formalin treatment, using CSBV purified from a natural outbreak. The specific IgY was produced by immunization of white leghorn hens with the vaccine. An enzyme-linked immunosorbent assay using purified CSBV as the coating antigen revealed that the anti-CSBV IgY titer began increasing in the egg yolk on the 14th day post-immunization, reaching a peak on day 42 , and antiCSBV IgY remained at a high level until day 91. IgY isolated from the combinations of egg yolk collected between days 42-91 was purified by PEG and ammonium sulfate precipitation. In three repeated protection experiments using $A$. cerana larvae inoculated with CSBV, the survival rate of larvae was more than $80 \%$, and the titer of anti-CSBV IgY was more than $2^{5}$ and $2^{4}$ when the larvae were fed lgY $24 \mathrm{~h}$ after and before inoculation with CSBV, respectively. Therefore, 400 colonies infected with CSBV were treated by feeding sugar containing IgY solutions with an antibody titer of $2^{5}$, and the cure rate was 95-100\%. Three hundred susceptible colonies were protected by feeding the larvae with sugar containing IgY solutions with an antibody titer of $2^{4}$, and the protection rate was $97 \%$. The results clearly suggest that a specific IgY was obtained from hens immunized with an inactivated-CSBV vaccine; this may be a novel method for controlling CSBV infection.

Keywords: Chinese sacbrood virus, egg yolk antibodies, IgY against CSBV, preparation of IgY, antibody titer, passive immunotherapy, controlling of CSBV infection

\section{INTRODUCTION}

A large number of Apis cerana and Apis mellifera are raised in China, which provide a wealth of nutrient-rich beehive products and pollinate a wide variety of crops and flowers. However, honeybees often die or escape, and it is possible for the entire colony to collapse because of infection with pathogens such as viruses, bacteria, fungi, parasites, and protozoa (Schmid-Hempel and Schmid-Hempel, 1998; Liu et al., 2010). Among honeybee pathogens, Chinese sacbrood virus 
(CSBV) is the most serious threat to bee health and has caused widespread concern among beekeepers and researchers. CSBV primarily affects the brood of honeybees and results in larval death (Ghosh et al., 1999), as well as reducing the lifespan of adult bees (Bailey, 1969, 1976). Larvae that are between 1 and 3 days old are most susceptible to CSBV infection. CSBV infection causes death in infected larvae, before or after they are capped; the tissue of infected larvae becomes liquefied, their body surface changes color, and larvae dry out shortly after death (Yan and Han, 2008). CSBV infection occurs mainly in spring, when brood rearing begins. Currently, CSBV is widespread in China and Southeast Asia.

As CSBV causes the death of honeybees, and even the collapse of entire colonies, it is often referred to as "bee cancer" by beekeepers. Outbreaks of CSBV have reduced the number of A. cerana colonies in Liaoning Province, China, from 40,000 to less than 20,000 in 2008 (Ma et al., 2011). Since 2008, A. cerana have been frequently infected by CSBV in this region of China, greatly affecting the region's apiculture (Zhang, 2012).

Currently, there are no specific treatments for CSBV infections of honeybees (Feng et al., 1998). Egg yolk antibodies known as immunoglobulin Y (IgY) have been widely used in the prevention and control of epidemic diseases, and for research purposes (Sotiropoulou et al., 2012; Vega et al., 2012; Han et al., 2014). Oral immunoglobulin therapy with egg yolk-derived antibodies against porcine transmissible gastroenteritis virus, porcine epidemic diarrhea virus (Huanzhong et al., 2012), white spot syndrome virus (Yong et al., 2006), and rotavirus (Sarker et al., 2007) immunoglobulin's were previously shown to achieve significant therapeutic effects against viral infections in clinical trials. However, IgY has not previously been used to prevent and treat CSBV.

This study was conducted to develop an IgY against CSBV from egg yolk. The inactivated oil-adjuvant vaccine was prepared by isolating and identifying CSBV, after which laying hens were vaccinated three times. Hen eggs were collected, and the specific IgY was prepared from egg yolk. Yolk antibodies were used in clinical treatment and were found to have significant effects on CSBV.

\section{MATERIALS AND METHODS}

\section{Purification and Confirmation of CSBV}

The infected A. cerana were collected from Kuandian, Liaoning Province $\left(40^{\circ} 43^{\prime} 46.80^{\prime \prime} \mathrm{N}, 124^{\circ} 46^{\prime} 40.55^{\prime \prime} \mathrm{E}\right)$. For virus purification, after infected $A$. cerana were weighed, the larvae were placed in sterile water (1.5 times their volume), and completely homogenized using a mortar and pestle. Following the methodology described by Ming-xiao et al. (2010), CSBV was purified using cesium chloride gradient centrifugation. The supernatant was filtered first through a $0.45-\mu \mathrm{m}$ cell filter, and then through a $0.22-\mu \mathrm{m}$ cell filter. The purified CSBV was fed to 2- or 3-day-old A. cerana larvae for virus passage. Eight days after larvae were inoculated with CSBV, CSBV was isolated and purified again from infected larvae using the methods described above. Subsequently, CSBV was identified by reverse transcription (RT) polymerase chain reaction (PCR) methodology to exclude black queen cell virus (BQCV), acute bee paralysis virus (ABPV), chronic bee paralysis virus (CBPV), deformed wing virus (DWV), Kashmir bee virus (KBV), and Israeli acute paralysis virus (IAPV), following the method of $\mathrm{Hu}$ et al. (2016). The CSBV virus samples, after demonstrating that they did not contain other viruses in addition to CSBV, were stored at $-80^{\circ} \mathrm{C}$ until further use.

\section{Preparation of the Inactivated Vaccine}

The protein content of the concentrated virus was determined using a BCA Protein Assay Kit (Thermo Scientific, Waltham, MA, United States). The protein concentration of the viral concentrated solution was diluted to $0.3 \mathrm{mg} / \mathrm{mL}$ using $0.01 \mathrm{M}$ phosphate-buffered saline (PBS), $\mathrm{pH}$ 7.4. After dilution, the viral solution was treated with $0.4 \%$ formalin for $24 \mathrm{~h}$. Tween- 80 was added at an $8 \%$ volume of the viral diluents, mixed with the viral diluents, and used as the water phase. The mixture of the 1:10 volume ratio between Span-80 and No.10 white-oil was used as the oil phase, after sterilization at $121.3^{\circ} \mathrm{C}$. After homogenization by centrifugation at $8,000 \times \mathrm{g}$ for $10 \mathrm{~min}$, the oil phase was slowly added to the water phase at a 3:1 volume ratio, and the mixture of the oil phase and water phase was homogenized by centrifugation at $10,000 \times \mathrm{g}$ for $5 \mathrm{~min}$. The inactivated vaccine was produced as the $\mathrm{W} / \mathrm{O}$ type emulsion.

\section{Immunization of Hens}

In total, 150 white leghorn laying hens, 24 weeks of age, were immunized intramuscularly at three different sites with $1 \mathrm{~mL}$ of the inactivated vaccine; the immunization was performed three consecutive times, with 2 -week intervals. Additionally, a negative control was established by using non-immunized hens. Blood and egg samples were collected from the time of first vaccination, and then once per week during the experimental period. The blood was allowed to clot at $24-25^{\circ} \mathrm{C}$, and the centrifuged sera were stored at $-20^{\circ} \mathrm{C}$. The collected eggs were stored at $4^{\circ} \mathrm{C}$ before being used to prepare IgY. The antibody titer in the serum was monitored to confirm increased antibody levels after the booster doses. In total, 15 non-immunized hens were processed in a similar manner.

\section{Enzyme-Linked Immunosorbent Assay}

An enzyme-linked immunosorbent assay (ELISA) was conducted to check the serum antibody titer. The 96-well microtiter plates (Gibco, Grand Island, NY, United States) were coated overnight at $4^{\circ} \mathrm{C}$ with $\mathrm{PBS}$ ( $\mathrm{pH} 7.4$ ), containing $1 \mu \mathrm{g} / \mathrm{mL}$ of the purified CSBV antigen. CSBV-coated plates were washed three times with 0.05\% Tween-20 in PBS (PBST). The wells were blocked with $300 \mu \mathrm{L}$ of PBS containing $3 \%$ skim milk for $1 \mathrm{~h}$ at $37^{\circ} \mathrm{C}$. The wells were washed again three times with PBST. Next, $100 \mu \mathrm{L}$ of appropriately diluted serum (1:1000 dilution) preparations from immunized and non-immunized hens at different time intervals were added to the wells. The plates were then incubated at $37^{\circ} \mathrm{C}$ for $1 \mathrm{~h}$, and washed three times with PBST, before adding horseradish peroxidase-conjugated rabbit anti-chicken IgG (Sigma Chemical Co., St. Louis, MO, United States) diluted 
$(1: 5,000)$ in $\mathrm{PBS}$, and incubating for $45 \mathrm{~min}$ at $37^{\circ} \mathrm{C} .3,3^{\prime}, 5,5^{\prime}-$ Tetramethylbenzidine substrate solution was added, and plates were incubated for $15 \mathrm{~min}$, before sulfuric acid was added to stop the reaction. The optical density (OD) was measured on an ELISA plate reader, using a 450-nm filter, and the ODs were statistically analyzed using statistical software SPSS17.

\section{Purification of IgY Antibodies From Egg Yolk}

When the titer of the serum antibody was relatively stable, IgY antibodies were purified from combinations of the egg yolk collected. IgY antibodies were extracted from the yolk, which was separated from the white using an egg separator once a week from days 42 to 91 after the first immunization, according to the methods described by Polson et al. (1980) and Ko and Ahn (2007). Briefly, a volume of yolk was added to a $1 / 3$ volume of buffer containing $14 \%$ polyethylene glycol (PEG) $6000(\mathrm{w} / \mathrm{v})$, and was stirred at $22-26^{\circ} \mathrm{C}$ for $30 \mathrm{~min}$. After the mixture was centrifuged at $5,000 \times g$ for $20 \mathrm{~min}$ at $10^{\circ} \mathrm{C}$, the supernatant (filtered through four layers of sterile gauze) was collected. Subsequently, PEG6000 was added to the filtrate with gentle stirring to adjust the final polymer concentration to $12 \%$ (w/v). The pellet was collected by centrifugation, and dissolved in the original volume of yolk in PBS to prepare the solution containing IgY. Solid ammonium sulfate was dissolved in the solution containing IgY, adjusted to $50 \%$ saturation, and stirred for approximately $12 \mathrm{~h}$ at $4^{\circ} \mathrm{C}$. Collected centrifuged pellets were washed with $33 \%$ saturated ammonium sulfate. The content was desalted by dialysis. Purified IgY antibodies were sterilized with a $0.22-\mu \mathrm{m}$ membrane filter and stored at $-20^{\circ} \mathrm{C}$.

Purified IgY antibodies were diluted by $2^{2}, 2^{3}, 2^{4}, 2^{5}, 2^{6}, 2^{7}, 2^{8}$, and $2^{9}$, and the titer of combinations of $\operatorname{IgY}$ antibodies against CSBV were determined by the above described ELISA method once a week from days 42 to 91 . The IgY antibodies titer were statistically analyzed by the OD of same dilutions at different time intervals as aroup, using the statistical software SPSS 17.

\section{SDS-PAGE}

As described previously (Sentila et al., 2013), the above purified IgY antibodies were determined by sodium dodecyl sulfate polyacrylamide gel electrophoresis (SDS-PAGE) (Hatta et al., 1997), with a $4 \%$ stacking gel and $10 \%$ separating gel.

\section{Viral Neutralization Assay}

The VN assay, used to detect the ability of IgY antibodies to neutralize CSBV, was modified from the mammalian $\mathrm{VN}$ assay protocol based on previously described methods (OIE, 2010.). The CSBV VN assay was performed as follows: First, CSBV were incubated with two-fold serial dilutions of IgY antibodies for $1 \mathrm{~h}$ at $37^{\circ} \mathrm{C}$. Next, a total of 140 2-day-old larvae were retrieved from the same colony in Jinzhou Medical University Farm $\left(41.12^{\circ} \mathrm{N}\right.$, $121.15^{\circ} \mathrm{E}$ ), following $\mathrm{Hu}$ et al. (2016), and randomly distributed into seven groups, with each group containing 20 larvae, and then each larva in groups 1-6 was fed $10 \mu \mathrm{L}$ of virus and IgY suspension containing $1.25 \times 10^{7}$ copies of CSBV to reach the $100 \%$ mortality rate (Hu et al., 2016) and the IgY titer at $2^{2}, 2^{3}, 2^{4}$,
$2^{5}$, and $2^{6}$, mixed with an equal amount of basic larval diet (BLD; $37 \%$ sterile water, $6 \%$ fructose, $50 \%$ royal jelly, $6 \%$ glucose, and $1 \%$ yeast extract) (Liu and Zeng, 2010), which was subsequently used for daily feeding. Group 7 served as a control. Larvae were kept under $95 \%$ relative humidity at $34^{\circ} \mathrm{C}$. The virus neutralization titers were read as the last serum dilution showing protection of the larva. The above assay was performed in triplicate. The dead larvae were tested with RT-PCR for the following viruses during the VN assay: BQCV, ABPV, CBPV, DWV, KBV, IAPV, and CSBV.

\section{Protection of A. cerana Larvae Inoculated With CSBV}

Two-days-old A. cerana larvae were used to verify the protective effect of IgY against CSBV. A total of 280 2-day-old larvae were retrieved from the same colony, following the method of Hu et al. (2016), and randomly distributed into 14 groups (termed groups 8-21), with each group containing 20 larvae. Groups 8-13 were inoculated with CSBV at $1.25 \times 10^{7}$ copies/larva (Hu et al., 2016). Group 14 and 21 served as virusfree controls. Groups 15-20 were fed with anti-CSBV-specific IgY titer at $2^{2}, 2^{3}, 2^{4}, 2^{5}$, and $2^{6}$ (after two-fold serial dilutions), and no anti-CSBV-specific IgY, respectively. To evaluate the curative effect on CSBV using the specific IgY, groups 8-13 were fed with anti-CSBV-specific IgY titer at $2^{2}, 2^{3}, 2^{4}, 2^{5}$, and $2^{6}$ (after two-fold serial dilutions), and no anti-CSBV specific IgY after inoculating with CSBV $24 \mathrm{~h}$, respectively. To evaluate the preventative effect on CSBV using the specific IgY, groups 15-20 were inoculated with CSBV at $1.25 \times 10^{7}$ copies/larva, $24 \mathrm{~h}$ after being inoculated with IgY. The above assay was performed in triplicate.

Each larva was fed $10 \mu \mathrm{L}$ of virus or IgY suspension mixed with an equal BLD, and was reared according to the above described rearing protocol.

The dead larvae were detected by RT-PCR for the following viruses during the protection experiments: BQCV, ABPV, CBPV, DWV, KBV, IAPV, and CSBV.

\section{Application of Egg Yolk Antibodies}

Four hundred colonies infected with CSBV were diagnosed by clinical symptoms or RT-PCR detection from May to August in 2013 and 2014 in Huairen, Liaoning Province $\left(40.76^{\circ} \mathrm{N}\right.$, $\left.120.85^{\circ} \mathrm{E}\right)$; Kuandian, Liaoning Province $\left(40.75^{\circ} \mathrm{N}, 124.77^{\circ} \mathrm{E}\right)$; and Chengde, Hebei Province $\left(40.95^{\circ} \mathrm{N}, 117.96^{\circ} \mathrm{E}\right)$. Of the 400 CSBV-infected colonies, 20 colonies escaped because of the loss of the queen and drone spawn, and 153 colonies were confirmed to be CSBV-positive by RT-PCR. If, in a Colony, (1) capped brood was not normally sealed, became dark black, down sunken and perforated, (2) there are a large number of sick and dead larvae in the honeycomb with the capped brood not normally sealed, (3) around the entrance of the colonies, even very few capped brood sealed and larvae were observed, and (4) the production capacity of worker bees to gather honey and pollen were reduced and disordered, it was designated as serious infection groups. If, in a colony, (1) CSBV infection was detected by RT-PCR analysis, (2) the larvae infected showed head warped upward, body surface change white, but (3) the production capacity of 
worker bees to gather honey and pollen was normal and orderly, very few capped broods were not normally sealed, and (4) no sick and dead larvae were observed around the entrance of the colonies, it was designated the moderate infection group ( $n=227$ colonies). The reasons why the dead larvae were not observed were probably that there were a smaller number of dead larvae, and they were cleaned by worker bees before observation. Among the $400 \mathrm{CSBV}$-infected colonies, there were four escaped colonies, 39 serious infection colonies, and 60 moderate infection colonies in Huairen, Liaoning Province; 11 escaped colonies, 71 serious infection colonies, and 115 moderate infection colonies in Kuandian, Liaoning Province; and five escaped colonies, 43 serious infection colonies, and 52 moderate infection colonies in Chengde, Hebei Province. The aforementioned 400 CSBVinfected colonies were treated using purified $\operatorname{IgY}$ diluted to a titer of $2^{5}$ with PBS containing sugar. The solution was fed to infected $A$. cerana $\left(20 \mathrm{~mL}\right.$ day $^{-1}$ colony $\left.^{-1}\right)$ by direct feeding with continuous feeding three times, followed by feeding once a day. Five A. cerana larvae (4 to 6-days-old) were randomly selected from serious infection groups and moderate infection group on $2,3,4,5,6,7$, and 8 days after treatment using purified IgY in Huairen, Liaoning Province, Kuandian, Liaoning Province, and Chengde, Hebei Province, respectively; totally 210 A. cerana larvae were collected and subjected to RT-PCR analysis for CSBV.

Three hundred susceptible colonies that had previously been infected with CSBV, but 1 year later, in which CSBV was not detected by RT-PCR, were protected using purified IgY before the brood rearing began in March 2015 in Kuandian, Liaoning Province. IgY was diluted to a titer of $2^{4}$ with PBS, and then sugar was dissolved in the solution. The solution was fed to 300 healthy A. cerana colonies $\left(20 \mathrm{~mL}\right.$ day $^{-1}$ colony $\left.^{-1}\right)$ by direct feeding with continuous feeding three times, followed by daily feeding.

Honeybee belongs to the social insect, which there are about 20-40 thousands of honeybee in a colony, a queen spawns more than 1,000 eggs a day, and the normal lifetime of honeybee is about a month or so during the breeding period. So the number of

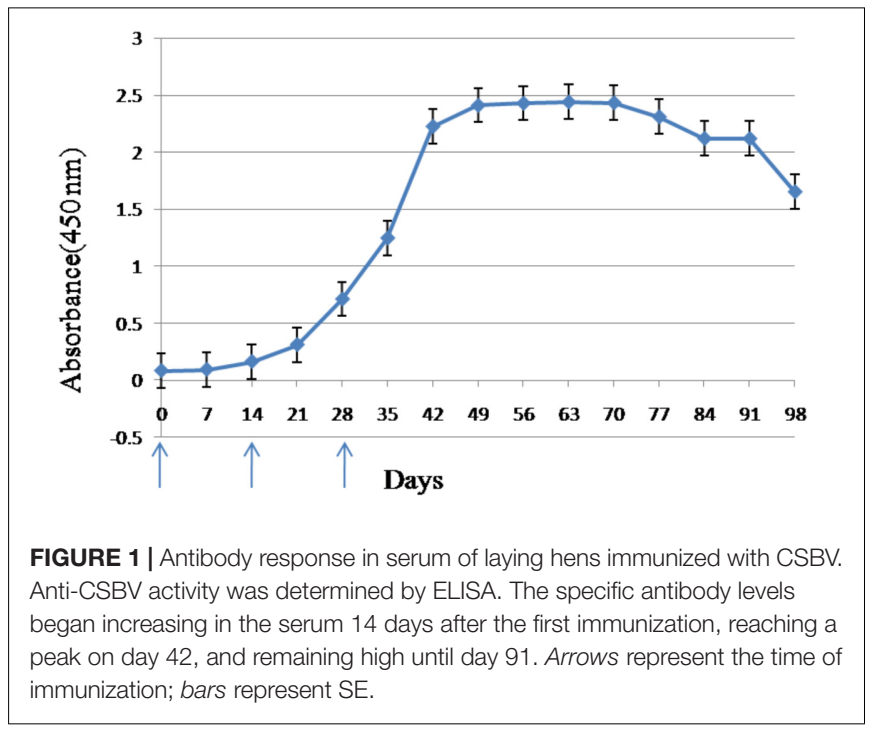

honeybee cannot be accurately counted. Therefore, the standard for the recovery of colonies infected with CSBV were as follows:

(a) No sick and dead larvae were observed in a honeycomb and around the entrance of the colonies.

(b) The production capacity of worker bees to gather honey and pollen was normal and orderly.

(c) More than $50 \%$ capped brood were normally sealed and connected to one another as a whole.

(d) CSBV could not be detected using RT-PCR.

\section{Stability of IgY in Terms of Route of Oral}

In total, 20 worker honeybees were sacrificed for tissue dissection, respectively. Each worker honeybee was fixed onto the wax top of a dissecting dish with insect pins, and the abdomen was opened with scissors. Honey sac were carefully separated and removed with forceps under a dissecting microscope. The contents of the honey sac are sucked out with syringe (volume $1 \mathrm{~mL}$ ), and dripped into $200 \mu \mathrm{L}$ of appropriately diluted IgY titer at $2^{5}$ (equal to the dose used to treat 20 bees), respectively. The IgY interacted with the contents of the honey sac for 12 and $24 \mathrm{~h}$ at $37^{\circ} \mathrm{C}$. Then, the supernatants of these suspensions were separated by centrifugation at $8,000 \times g$, and subjected to subsequent $\operatorname{IgY}$

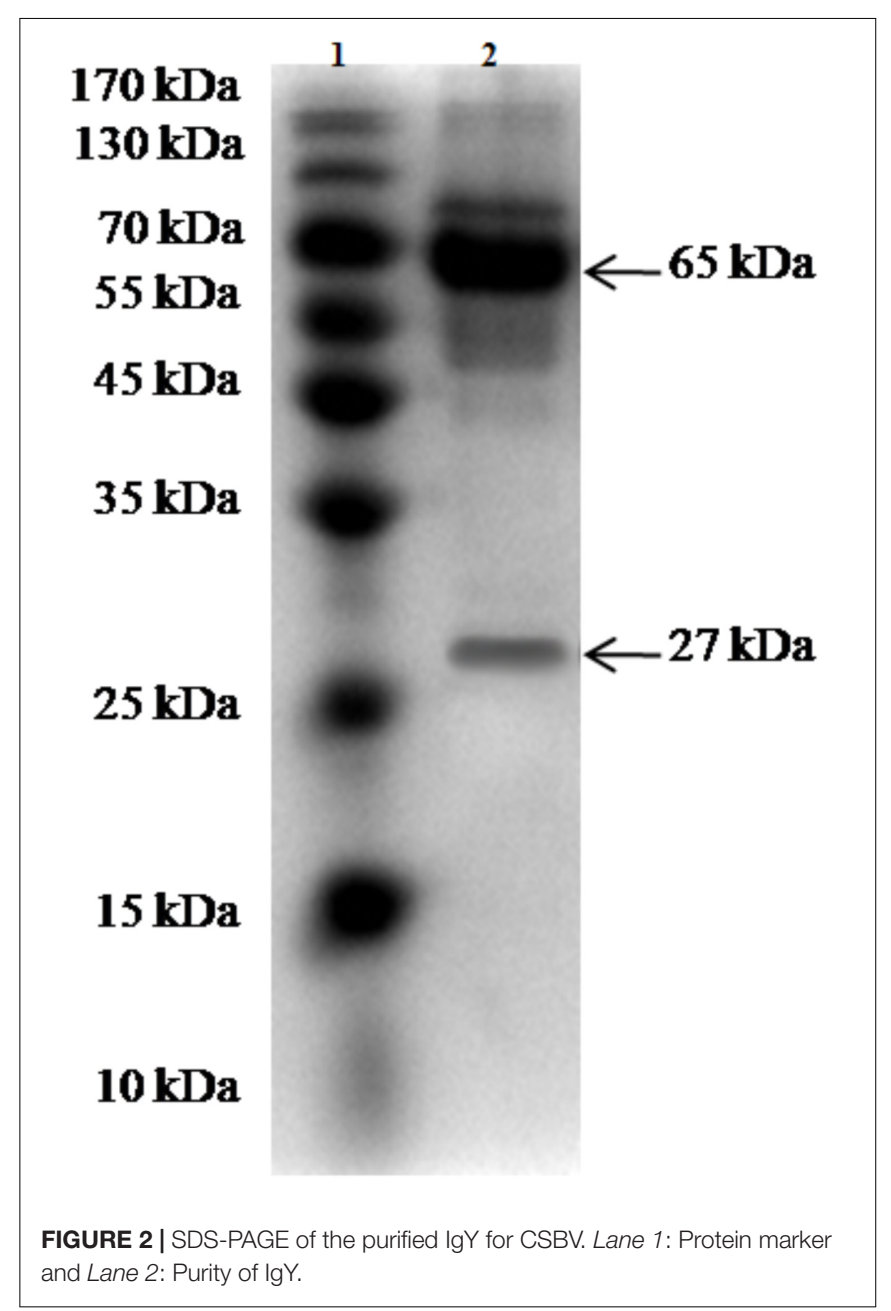


titer detection using ELISA. Additionally, the same operation was performed to detect the IgY titer for BLD containing IgY titer at $2^{5}$ and IgY antibody original solution titer at $2^{5}$.

\section{RESULTS}

\section{Determination of Serum Antibody Titers}

The ELISA assay revealed that the anti-CSBV antibody titer began to rise in the sera of inoculated white leghorn hens 14 days after the first immunization. The anti-CSBV antibody titer peaked on day 42 and was then maintained at high levels from days 42 to 91 (Figure 1). Eggs were collected from days 42 to 91.

\section{Titer of Combinations of IgY Antibodies Against CSBV by ELISA}

The purity and molecular weights of IgY antibodies against CSBV were determined by SDS-PAGE. Under reduced conditions, the IgY antibodies against CSBV presented two bands of approximately 65 and $27 \mathrm{kDa}$, respectively (Figure 2). Using ELISA, the OD ratio of combinations of anti-CSBV specific IgY to the negative control was $>1.5$ at $2^{2}, 2^{3}, 2^{4}, 2^{5}, 2^{6}, 2^{7}$, and $2^{8}$ dilutions, while the $2^{9}$ dilution was $<1.5$. The results showed that the titer of combinations of anti-CSBV specific IgY was $2^{8}$ (Figure 3).

\section{VN Assay}

Triplicate experiments revealed that the mortality rates of the larvae were $65-75 \%(14 / 20,12 / 20$, and $15 / 20), 40-50 \%$
(10/20, 9/20, and 8/20), 25-35\% (7/20, 5/20, and 7/20), 10$20 \%(3 / 20,2 / 20$, and $4 / 20), 10-20 \%(2 / 20,4 / 20$, and $2 / 20)$, $100 \%(20 / 20)$, and $10-20 \%(3 / 20,3 / 20$, and $4 / 20)$ in groups 1 7 , respectively, and these larvae died before pupation (Table 1 ), but the death time of larvae in groups 2 and 3 tended to be delayed.

All dead larvae found during the VN assay were analyzed by RT-PCR, and the results showed that all of the other honeybee viruses were undetectable, whereas CSBV was detectable.

\section{Protection of $A$. cerana Larvae Inoculated With CSBV}

Triplicate experiments revealed that the mortality rates of the larvae were $85-95 \%(19 / 20,19 / 20$, and $17 / 20), 60-70 \%(12 / 20$, $14 / 20$, and $12 / 20), 35-50 \%(8 / 20,10 / 20$, and $7 / 20), 20-30 \%(5 / 20$, $4 / 20$, and $6 / 20), 10-15 \%(2 / 20,3 / 20$, and $3 / 20), 100 \%(20 / 20)$, and $10-15 \%(2 / 20,3 / 20$, and $2 / 20)$ in groups $8-14$, respectively, and these larvae died before pupation (Table 2), but the death time of larvae in groups 10 and 11 tended to be delayed. The survival rate was not $100 \%$ because of the death of larvae due to artificial circumstances.

Three repeated experiments indicated that the mortality rates of the larvae were $60-80 \%(15 / 20,12 / 20$, and $16 / 20)$, $45-55 \%(11 / 20,11 / 20$, and $9 / 20), 25-40 \%(7 / 20,5 / 20$, and $8 / 20), 10-20 \%(2 / 20,4 / 20$, and $2 / 20), 10-20 \%(3 / 20,4 / 20$, and $2 / 20), 100 \%(20 / 20)$, and $10-20 \%(2 / 20,4 / 20$, and $3 / 20)$ in groups 15-21, respectively, and these larvae died before pupation (Table 3) but the death time of larvae in group 17 tended to be delayed.

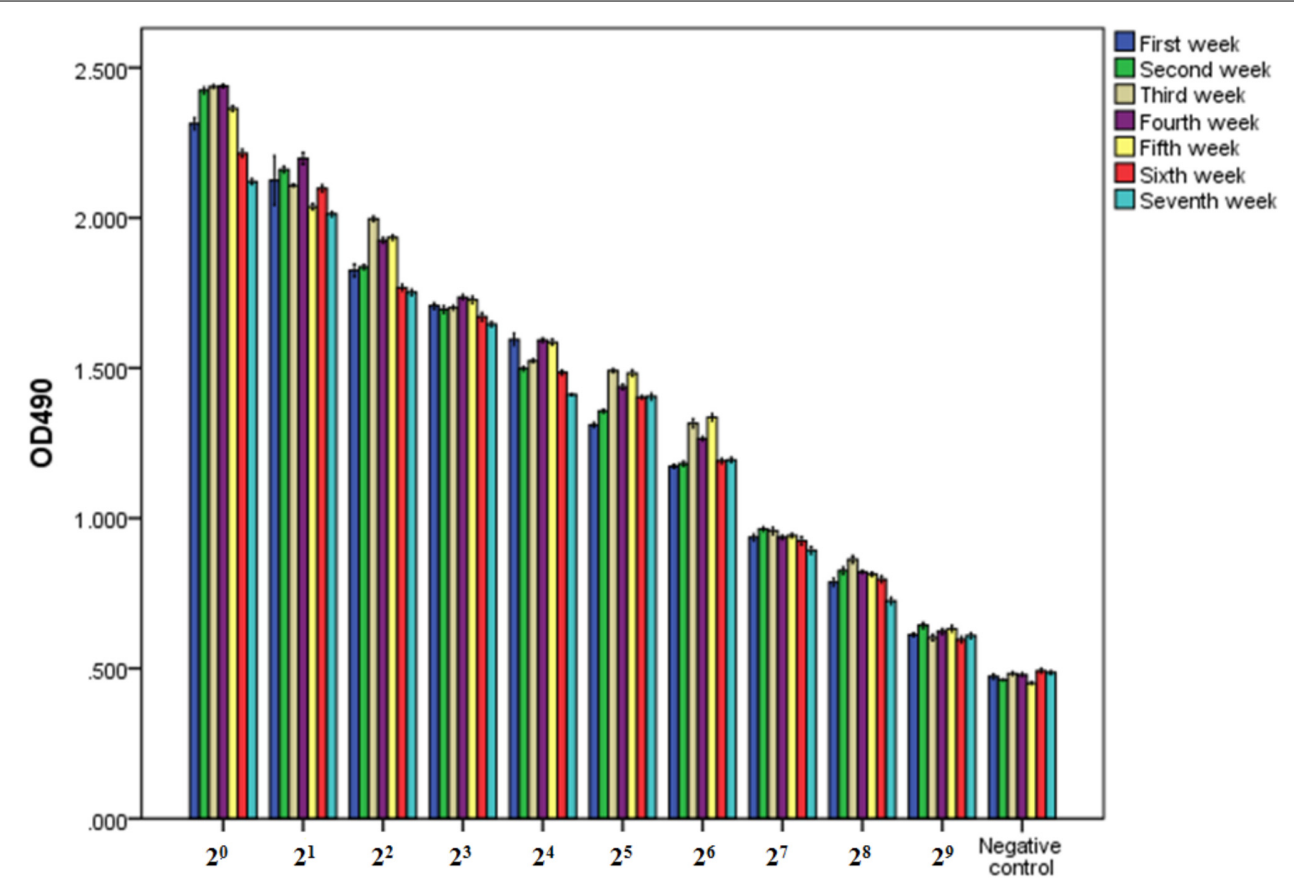

FIGURE 3 | Titer of combinations of IgY antibodies against CSBV detected by ELISA once a week from days 42 to 91 after the first immunization. The OD ratio of combinations of anti-CSBV specific IgY to the negative control was $>1.5$ at 22, 23, 24, 25, 26, 27, and 28 dilutions, while the 29 dilution was $<1.5$. The results indicated that the titer of combinations of anti-CSBV-specific IgY is 28. Bars represent SE. 
TABLE 1 | Viral neutralization assay.

\begin{tabular}{lccccc}
\hline Group & \multicolumn{4}{c}{ The number of dead larvae at different time points(a/b/c) } \\
\cline { 2 - 5 } & $\mathbf{2 4} \mathbf{h}$ & $\mathbf{4 8} \mathbf{h}$ & $\mathbf{7 2} \mathbf{h}$ & $\mathbf{9 6} \mathbf{h}$ & $\mathbf{1 2 0} \mathbf{h}$ \\
\hline 1 & $3 / 1 / 0$ & $2 / 4 / 4$ & $7 / 3 / 7$ & $2 / 4 / 4$ & $0 / 0 / 0$ \\
2 & $2 / 0 / 1$ & $0 / 3 / 1$ & $3 / 3 / 2$ & $5 / 2 / 3$ & $0 / 1 / 1$ \\
3 & $0 / 1 / 0$ & $1 / 0 / 3$ & $0 / 0 / 1$ & $3 / 2 / 0$ & $3 / 2 / 3$ \\
4 & $1 / 0 / 1$ & $0 / 1 / 0$ & $1 / 2 / 1$ & $0 / 1 / 0$ & $0 / 0 / 0$ \\
5 & $0 / 1 / 1$ & $1 / 1 / 0$ & $2 / 0 / 0$ & $0 / 2 / 1$ & $0 / 0 / 0$ \\
6 & $1 / 2 / 1$ & $8 / 9 / 12$ & $9 / 8 / 7$ & $2 / 1 / 0$ & $0 / 0 / 0$ \\
7 & $2 / 0 / 1$ & $1 / 1 / 1$ & $0 / 2 / 1$ & $0 / 1 / 0$ & $0 / 0 / 0$ \\
\hline
\end{tabular}

$a, b$, and $c$ represent the number of dead larvae from three repeated experiments.

TABLE 2 | The curative effect on CSBV of using the specific lgY.

\begin{tabular}{llllll}
\hline \multirow{2}{*}{ Group } & \multicolumn{4}{c}{ The number of dead larvae at different time points(a/b/c) } \\
\cline { 2 - 6 } & $\mathbf{2 4} \mathbf{h}$ & $\mathbf{4 8} \mathbf{h}$ & $\mathbf{7 2} \mathbf{~}$ & $\mathbf{9 6} \mathbf{~}$ & $\mathbf{1 2 0} \mathbf{~}$ \\
\hline 8 & $5 / 4 / 3$ & $9 / 8 / 5$ & $4 / 7 / 7$ & $1 / 0 / 2$ & $0 / 0 / 0$ \\
9 & $3 / 2 / 3$ & $3 / 4 / 4$ & $5 / 6 / 3$ & $1 / 2 / 2$ & $0 / 0 / 0$ \\
10 & $1 / 0 / 2$ & $2 / 1 / 0$ & $3 / 4 / 1$ & $1 / 5 / 4$ & $1 / 0 / 0$ \\
11 & $2 / 1 / 1$ & $1 / 0 / 1$ & $1 / 2 / 2$ & $1 / 0 / 0$ & $0 / 1 / 2$ \\
12 & $0 / 0 / 0$ & $1 / 2 / 2$ & $0 / 1 / 0$ & $1 / 0 / 1$ & $0 / 0 / 0$ \\
13 & $8 / 9 / 9$ & $7 / 8 / 6$ & $4 / 3 / 3$ & $1 / 0 / 2$ & $0 / 0 / 0$ \\
14 & $2 / 1 / 0$ & $0 / 2 / 1$ & $0 / 0 / 0$ & $0 / 0 / 1$ & $0 / 0 / 0$ \\
\hline
\end{tabular}

$a, b$, and $c$ represent the number of dead larvae from three repeated experiments.

TABLE 3 | The preventative effect on CSBV of using the specific IgY.

\begin{tabular}{lccccc}
\hline \multirow{2}{*}{ Group } & \multicolumn{4}{c}{ The number of dead larvae at different time points(a/b/c) } \\
\cline { 2 - 6 } & $\mathbf{2 4} \mathbf{h}$ & $\mathbf{4 8} \mathbf{h}$ & $\mathbf{7 2} \mathbf{h}$ & $\mathbf{9 6} \mathbf{~}$ & $\mathbf{1 2 0} \mathbf{~}$ \\
\hline 15 & $4 / 1 / 0$ & $2 / 4 / 3$ & $6 / 3 / 8$ & $3 / 4 / 5$ & $0 / 0 / 0$ \\
16 & $2 / 0 / 1$ & $1 / 2 / 2$ & $3 / 5 / 3$ & $5 / 4 / 3$ & $0 / 0 / 0$ \\
17 & $0 / 1 / 0$ & $1 / 0 / 3$ & $0 / 1 / 1$ & $3 / 2 / 1$ & $3 / 1 / 3$ \\
18 & $2 / 0 / 0$ & $0 / 1 / 1$ & $0 / 2 / 1$ & $0 / 1 / 0$ & $0 / 0 / 0$ \\
19 & $0 / 1 / 1$ & $1 / 1 / 0$ & $2 / 0 / 0$ & $0 / 2 / 1$ & $0 / 0 / 0$ \\
20 & $1 / 2 / 1$ & $8 / 9 / 12$ & $9 / 8 / 7$ & $2 / 1 / 0$ & $0 / 0 / 0$ \\
21 & $2 / 0 / 1$ & $1 / 1 / 0$ & $0 / 2 / 1$ & $1 / 0 / 0$ & $0 / 0 / 0$ \\
\hline
\end{tabular}

$a, b$, and $c$ represent the number of dead larvae from three repeated experiments.

All dead larvae found during the protection experiments were analyzed by RT-PCR, and the results showed that all of the other honeybee viruses were undetectable, whereas CSBV was detectable.

\section{Application of Egg Yolk Antibodies}

In the $400 \mathrm{CSBV}$-infected colonies, 20 colonies were not treated because of loss of the queen and drone spawn. In the 165 colonies in the serious infection group, no sick and dead larvae were observed in a honeycomb and around the entrance of the colonies (Conforming to standard a), and the production capacity of worker bees to gather honey and pollen restored from days 7 to 13 after treatment with $\operatorname{IgY}$ (Conforming to standard b), and the capped broods were normally formed and connected to one another as a whole(Conforming to standard c) from days 18 to 21 after treatment with IgY (Figures 4A-D). CSBV could be detected using RT-PCR from days 2 to 6, but could not be detected from the 7th day (Table 4), (Conforming to standard d), and the capped broods were normally formed after treatment purified IgY in Huairen, Liaoning Province and Chengde, Hebei Province, respectively. CSBV could be detected using RT-PCR from days 2 to 5 , but could not be detected from the 6th day (Table 4), and the capped broods were normally formed, after treatment with purified IgY in Kuandian, Liaoning Province. In the 215 colonies in the moderate infection group, no larvae whose head warped upward and body surface change white were observed (Conforming to standard a), new capped broods were normally formed 10 to 14 days after treatment with IgY (Figures 4E-H). CSBV could be detected using RT-PCR from days 2 to 3 , but could not be detected from the 4 th day (Table 4) (Conforming to standard d), and the capped broods were normally formed after treatment with purified IgY in the three bee farms (Conforming to standard b). The infected swarm bees were cured after approximately 1 month, and the cure rate was $95-100 \%$ according to the standard for the recovery of colonies infected with CSBV.

From March to September 2015, which is the period of A. cerana breeding in Kuandian, Liaoning Province, 291 of 300 colonies subjected to prevention treatment with purified IgY bred normally, produced honey, and pollinated plants, while the other nine colonies were diagnosed with CSBV infections, as detected by RT-PCR. The capped broods were not normally sealed, and no larvae were removed from the colony. These results indicate a protection rate of $97 \%$.

\section{Stability of IgY in Terms of Route of Oral}

Comparison with IgY antibody original solution, the titer of IgY antibody interacting with the contents of the honey sac and BLD for 12 and $24 \mathrm{~h}$ showed no differences; they were still $2^{5}$.

\section{DISCUSSION}

In China, CSBV frequently infects A. cerana, and negatively affects the region's apiculture. This virus can also cross the species barrier to cause the death of A. mellifera larvae (Sun et al., 2017). Additionally, SBV infections of $A$. mellifera are widespread and cause disease worldwide, influencing the production of bee products and plant pollination (Cavigli et al., 2016; Desai and Currie, 2016; Tsevegmid et al., 2016).

In recent years, some CSBV prevention and control schemes have been studied, including feeding $A$. mellifera with royal jelly, silver ion, CSBV dsRNA, and SP6 (Zhang et al., 2014, 2016; Ahn et al., 2015; Shen et al., 2017). However, these measures are still in the research stage, and CSBV infections have not been completely controlled. Traditional Chinese medicine treatment may be useful for the control of CSBV, but the effects of such treatment are slow, and traditional Chinese medicines have a poor cure rate for serious infection colonies, likely because these measures do not directly inactivate the virus, but rather improve resistance to the virus through immune 


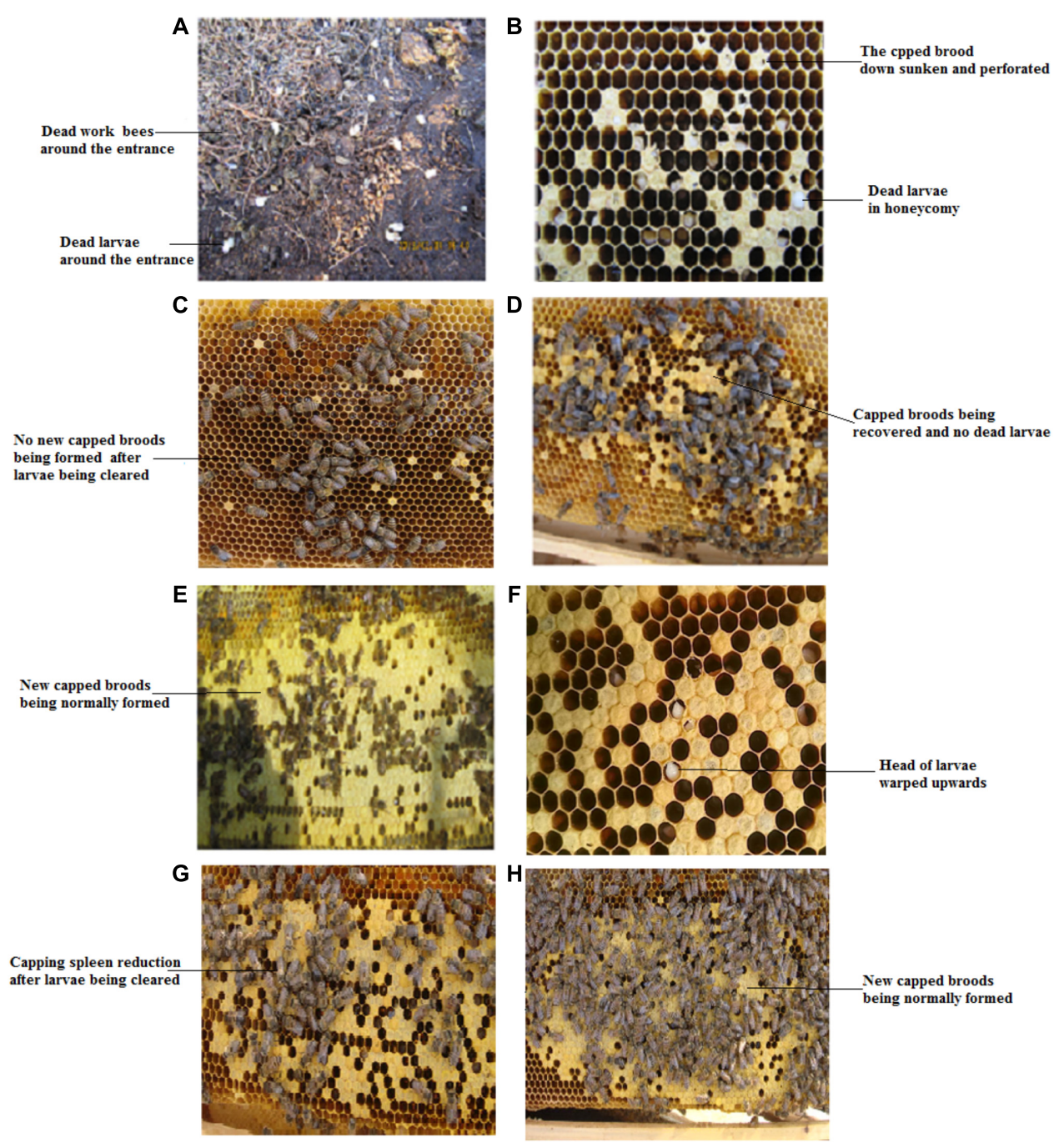

FIGURE 4 | Clinical symptoms of Apis cerana larvae infected with CSBV, and effect of treatment with anti-CSBV IgY. (A) Numerous larvae were dragged out of the colony, and dead worker bees were observed in the serious infection group. (B) Capped broods not being normally sealed, down sunken and perforated, were observed in the serious infection group. (C) No new capped broods being formed after larvae infected with CSBV being cleared in the serious infection group. (D) New capped broods begin to be formed, and no larvae were dragged out of the colony from 7 to 13 days after lgY treatment in the serious infection group. (E) The heads of larvae infected with CSBV were warped upward. (F) The capped brood was normally sealed from 18 to 21 days after lgY treatment. (G) Capping spleen reduction after larvae infected with CSBV being cleared in the moderate infection group. (H) New capped broods were normally formed 10 to 14 days after IgY treatment in the moderate infection group.

TABLE 4 | A total of 210 A. cerana larvae were randomly selected to detect CSBV by RT-PCR.

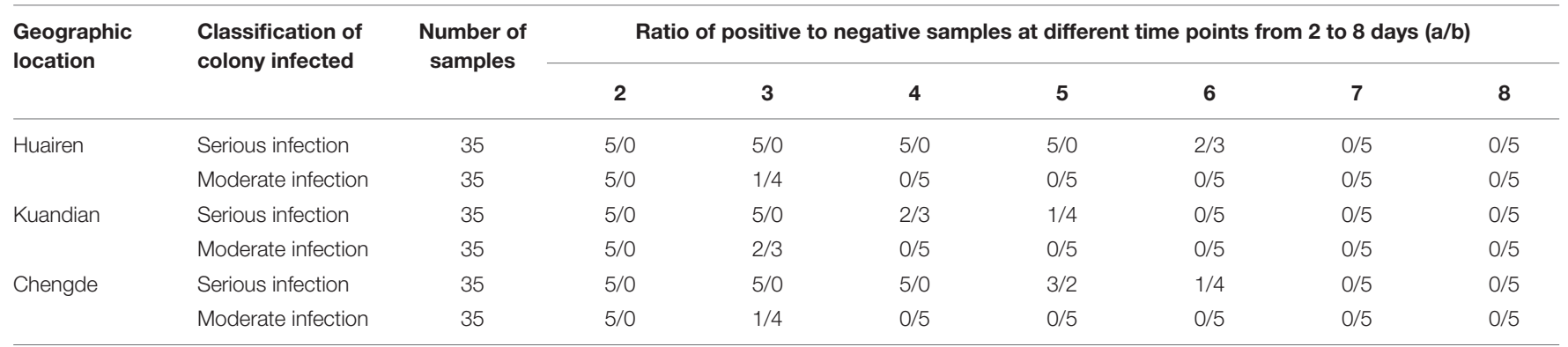

$a$ and $b$ represent the number of positive and negative samples for detecting CSBV by RT-PCR, respectively. Number of sample 35 means that 5 A. cerana larvae were randomly selected on $2,3,4,5,6,7$, and 8 days after treatment. 
regulation (Hanrong, 2000). Furthermore, A. cerana often refuse to feed on traditional Chinese medicines or avoid them due to the strong odor, which may result in the entire colony being destroyed. Specific IgY antibodies are increasingly used in passive immunotherapy for infectious diseases in recent years, and IgY antibodies are safe, inexpensive, and have no known side effects.

Mainly, five factors influence the development and production of specific IgY: The dose and molecular weight of the target antigen, the type of adjuvant used, the route of application, the immunization frequency, and the interval between immunizations (Schade and Hlinak, 1996). In this study, the titer of IgY antibodies against CSBV began increasing in the serum on day 14 after the first immunization, reaching a peak on day 42, and then remained at a high level until day 91, and the titer of combinations of anti-CSBV specific IgY was $2^{8}$ from days 42 to 91 . These results suggest that the collected eggs can be used to produce a large amount of IgY from days 42 to 91 after the first immunization, and the target antigen (inactivated CSBV vaccine) and immunization program, using continuous immunization at 2-week intervals, was suitable for preparing anti-CSBV IgY.

Various IgY extraction methods were reviewed in detail by De Meulenaer and Huyghebaert (2001); for review, see Schade et al., 2005). These methods include the water dilution methods (Kim and Nakai, 1996), ammonium or sodium sulfate precipitation method (Akita and Nakai, 1992), PEG method precipitation method (Polson et al., 1985; Polson, 1990), dextran sulfate precipitation method (Jensenius et al., 1981), precooled propane and acetone method (Bade and Stegemann, 1984), and water dilution ultrafiltration method (Chen, 2010). In order to select a suitable IgY extraction method, important influencing factors should be taken into account, including the scale of extraction (laboratory or industrial), cost effectiveness, production equipment, and impact on the environment (waste management). Akita and Nakai (1993) compared the water dilution methods to other methods in terms of yield purity and activity of $\operatorname{IgY}$. The water extraction of $\operatorname{IgY}$ is sufficient to achieve good results, but Pauly et al. (2011) reported that IgYextraction by means of PEG-precipitation is very cost-effective and results in highly specific antibodies with a stable titer, and worked very well in a large number of different immunological assays.

The classical VN assay must be performed on susceptible animals (including chicken embryos) or cells, but CSBV cannot be cultivated in vitro because of the lack of appropriate culture cells. Additionally, only larvae are used in CSBV cultures, and they may die naturally under the conditions of artificial rearing. The protocol of the CSBV neutralization assay have to be modified based on previously described methods (OIE, 2010). In the three repeated $\mathrm{VN}$ assays, the mortality rate of the larvae was less than $20 \%$ when the titer of the anti-CSBV IgY was more than $2^{4}$. A $0 \%$ mortality rate was not achieved because the artificial rearing conditions were not identical to the natural growth conditions of honey bees, and because there are individual differences between larvae. This may also explain why larval mortality was not exactly the same in the three replicated experiments. Nonetheless, these results indicate that the survival rate of larvae that were fed with a mixture of CSBV and IgY interacting with each other (IgY at a certain titer and neutralized with CSBV) was consistent with that of larvae not inoculated with the virus. Thus, CSBV can completely neutralized by antiCSBV IgY at a certain titer, and when less than the optimum titer, CSBV was partially neutralized causing to the survival time of the larvae to be prolonged. Similar experimental results were revealed in the three repeated protection experiments of $A$. cerana larvae inoculated with CSBV. These results showed that anti-CSBV IgY can protect $A$. cerana larvae exposed to CSBV. Following this result, IgY was used to treat 400 infected bee colonies, and to prevent infection in 300 susceptible bee colonies. The cure rate was more than $95 \%$, and the protection rate was more than $97 \%$. The clinical applications show that IgY treatment of CSBV is fast-acting, effective, and specific, and has a high cure rate, with rapid recovery. Furthermore, IgY directly and rapidly binds to the virus; thus, IgY can be used for the emergency prevention of CSBV outbreaks.

Orally administered antibodies, like any other protein, are susceptible to denaturation by the acidic $\mathrm{pH}$ of the stomach and degradation by proteases (Hatta et al., 1993; Shimizu et al., 1993) in mammals and poultry. But IgY is relatively tolerant to pressure $\left(4,000 \mathrm{~kg} / \mathrm{cm}^{2}\right)$, high temperature $\left(75-80^{\circ} \mathrm{C}\right)$, and low $\mathrm{pH}$ value $(\mathrm{pH}=3)$ as reported, with no detectable inactivation of $\operatorname{IgY}$ in aqueous solutions with high sugar concentrations (Shimizu et al., 1994). In addition to increasing the fraction of immune reactive antibodies delivered locally into the gastrointestinal tract, microencapsulation has been used to protect IgY from gastrointestinal inactivation (Chang et al., 2002; Cho et al., 2005; Kovacs-Nolan and Mine, 2005) in mammals and poultry. In the present study, we observed that the IgY antibodies titer did not change in an in vitro simulation experiment of honey bees, and the specific anti-CSBV IgY antibodies could effectively prevent and control CSBV by orally administered antibodies. The reason for this may be that the physiological conditions of the digestive system and characteristics of digestibility and absorption of honey bee are different from those of mammals and poultry, or high sugar concentrations of the honey sac and BLD enhanced the stability of the IgY (Shimizu et al., 1994), but the mechanism of CSBV being prevented and treated by IgY should be studied in the future.

In summary, the results of this study indicated that "universal" passive immunotherapy using a specific IgY for CSBV is a novel method for controlling CSBV infections. These results also indicated that a large amount of low-cost specific antibodies can be produced using egg yolks from immunized laying hens. We will continue researching the mechanism underlying the action of IgY against CSBV in our laboratory.

\section{ETHICS STATEMENT}

The use of the experimental animals involved in the article is in compliance with the relevant provisions of the Animal Welfare and Ethics of Experimental Animals of the Experimental Animal Center of Jinzhou Medical University, China. 


\section{AUTHOR CONTRIBUTIONS}

LS and MM designed the study and wrote the manuscript. LS, ML, DF, QD, JW, LL, and MM performed the experiments and analyzed the data. All authors approved the final version of the manuscript.

\section{REFERENCES}

Ahn, A. J., Ahn, K. S., Suh, G. H., Noh, J. H., Kim, Y. H., Yoo, M. S., et al. (2015). Efficacy of silver ions against Sacbrood virus infection in the Eastern honey bee Apis cerana. J. Vet. Sci. 16, 289-295. doi: 10.4142/jvs.2015.16.3.289

Akita, E. M, and Nakai, S. (1992). Immunoglobulins from egg yolks: isolation and purification. J. Food Sci. 57, 629-634. doi: 10.1111/j.1365-2621.1992.tb08058.x

Akita, E. M, and Nakai, S. (1993). Comparison of four purification methods for the production of immunoglobulins from eggs laid by hens immunized with an enterotoxigenic Escherichia coli strain. J. Immunol. Method. 160, 207-214. doi: 10.1016/0022-1759(93)90179-B

Bade, H., and Stegemann, H. (1984). Rapid method of extraction of H antibodies from hen egg yolk. J. Immunol. Methods 72:42 doi: 10.1016/0022-1759(84) 90010-3

Bailey, L. (1969). The multiplication and spread of sacbrood virus of bees. Ann. Appl. Biol. 63, 483-491. doi: 10.1111/j.1744-7348.1969.tb02844.x

Bailey, L. (1976).Viruses attacking the hone y bee. Adv. Virus Res. 20, 271-304. doi: 10.1016/S0065-3527(08)60507-2

Cavigli, I., Daughenbaugh, K. F., Martin, M., Lerch, M., Banner, K., Garcia, E., et al. (2016). Pathogen prevalence and abundance in honey bee colonies involved in almond pollination. Apidolog 47, 251-266. doi: 10.1007/s13592-015-0395-5

Chang, H. M., Lee, Y. C., Chen, C. C., and Tu, Y. Y. (2002). Microencapsulation protects immunoglobulin in yolk (IgY) specific against Helicobacter pylori urease. J. Food Sci. 67, 15-20. doi: 10.1111/j.1365-2621.2002.tb11351.x

Chen, C. (2010).Application of ultrafiltration for isolation and purification of $\operatorname{IgY}$ from egg. Fine Spec. Chem. 18, 21-24.

Cho, Y. H., Lee, J. J., Park, I. B., Huh, C. S., Baek, Y. J., Park. (2005). Protective effect of microencapsulation consisting of multiple emulsification and heat gelation processes on immunoglobulin in yolk. J. Food Sci. 70, 149-151. doi: 10.1111/j.1365-2621.2005.tb07088.x

De Meulenaer, B., and Huyghebaert, A. (2001). Isolation and purification of chicken egg yolk immunoglobulins: a review. Food Agric. Immunol.13, 275-288. doi: 10.1080/09540100120094537

Desai, S. D., and Currie, R. W. (2016). Effects of wintering environment and parasite-pathogen interactions on honey bee colony loss in north temperate regions. PLoS One 11:e0159615. doi: 10.1371/journal.pone.0159615

Feng, J. X., Lu, X. Y., and Zhang, J. Q. (1998). Study on the purification, crystallization and structure of chinese sacbrood bee virus. J. Electron Micros. (in Chinese), 17, 387-388.

Ghosh, R. C., Ball, B. V., Willcocks, M. M., and Carter, M. J. (1999). The nucleotide sequence of sacbrood virus of the honey bee: an insect picorna-like virus. J. Gen. Virol. 80, 1541-1549. doi: 10.1099/0022-1317-80-6-1541

Han, L., Kitova, E. N., Tan, M., Jiang, X., and Klassen, J. S. (2014). Identifying carbohydrate ligands of a norovirus $\mathrm{P}$ particle using a catch and release electrospray ionization mass spectrometry assay. J. Am. Soc. Mass Spectrom. 25:111. doi: 10.1007/s13361-013-0752-4

Hanrong, Q. (2000). Prevention and treatment of Chinses sacbrood. Guangxi Anim. Husb. Veterin. 16, 28-31.

Hatta, H., Tsuda, K., Akachi, S., Kim, M., and Yamamoto, T. (1993). Productivity and some properties of egg yolk antibody (IgY) against human rotavirus compared with rabbit IgG. Biosci. Biotechnol. Biochem. 57, 450-454. doi: 10. 1271/bbb. 57.450

Hatta, H., Tsuda, K., Ozeki, M., Kim, M., Yamamoto, T., Otake, S., et al. (1997). Passive immunization against dental plaque formation in humans: effect of a mouth rinse containing egg yolk antibodies (IgY) specific to Streptococcus mutans. Caries Res. 31, 268-274. doi: 10.1159/000262410

Hu, Y., Fei, D., Jiang, L., Wei, D., Li, F., Diao, Q., et al. (2016). A comparison of biological characteristics of three strains of Chinese sacbrood virus in Apis cerana. Sci. Res. 6:37424.

\section{FUNDING}

This work was supported by grants from the Natural Science Foundation of China (No. 31772760), award for "Liaoning Distinguished Professor," and the Agricultural Science and Technology Innovation Program (No. CAAS-ASTIP-2018-IAR).

Huanzhong, C., Hai long, J., Jia li, Z., Hui, Z., Xin, Q. G. (2012). Study and application the hyperimmunnized Yolk antibodies of TGEV and PEDV in piglets. Chin. Anim. Husb. Vet. Med. 39, 173-175.

Jensenius, J. C., Andersen, I., Hau, J., Crone, M., and Koch, C. (1981). Eggs:conveniently packed antibodies. Methods for purification of yolk IgG. J. Immunol. Methods 46, 63-68. doi: 10.1016/0022-1759(81) 90333-1

Kim, H., and Nakai, S. (1996). Immunoglobulin separation from egg yolk: a serial filtration systeml. J. Food Sci. 61, 510-512. doi: 10.1111/j.1365-2621.1996. tb13144.x

Ko, K. Y., and Ahn, D. U. (2007). Preparation of immunoglobulin Y from egg yolk using ammonium sulfate precipitation and ion exchange chromatography. Poult. Sci. 86, 400-407. doi: 10.1093/ps/86.2.400

Kovacs-Nolan, J., and Mine, Y. (2005). Microencapsulation for the gastric passage and controlled intestinal release of immunoglobulin Y. J. Immunol. Methods 296, 199-209. doi: 10.1016/j.jim.2004.11.017

Liu, G., and Zeng, Z. (2010). Advances on technology of honeybee larvae reared in vitro and its application. J. Bee 30, 32-34.

Liu, X., Zhang, Y., Yan, X., and Han, R. (2010). Prevention of Chinese sacbrood virus infection in Apiscerana using RNA interference. Curr. Microbiol. 61, 422-428. doi: 10.1007/s00284-010-9633-2

Ma, M., C., Li, M., Wang, S., Yang, S., and Wang, S. (2011).Loop-mediated isothermal amplification for rapid detection of Chinese sacbrood virus. J. Virol. Methods 176, 115-119. doi: 10.1016/j.jviromet.2011.05.028

Ming-xiao, M., Ming, L., Chun-ying, Y., Pengfei, L., Yibo, Z., Yuhong, S., et al. (2010). Development of A RT-PCR method for determination of chinese sacbrood virus. Chin. J. Biologicals 23, 425-427.

OIE (2010). Manual of Standards for Diagnostic Tests and Vaccines. Paris: OIE.

Pauly, D., Chacana, P. A., Calzado, E. G., Brembs, B., Schade, R. (2011). IgY technology: extraction of chicken antibodies from egg yolk by polyethylene glycol (PEG) precipitation. J. Vis. Exp. 51:3084. doi: 10.3791/3084

Polson, A. (1990). Isolation of IgY from the yolks of eggs by a chloroform polyethylene glycol procedure. Immunol. Invest. 19, 253-258. doi: 10.3109/ 08820139009041840

Polson, A., Coetzer, T., Kruger, J., Von, M. E., and van, K. J. (1985). Improvements in the isolation of IgY from the yolks of eggs laid by immunized hens. Immunol. Invest. 14, 323-327. doi: 10.3109/08820138509022667

Polson, A., Von Wechmar, M. B., and Van Regenmortel, M. H. V. (1980). Isolation of viral IgY antibodies from yolks of immunized hens. Immunol .Commun. 9, 475-493. doi: 10.3109/08820138009066010

Sarker, S. A., Pant, N., Juneja, L. R., and Hammarström, L. (2007). Successful treatment of rotavirus-induced diarrhoea in suckling mice with egg yolk immunoglobulin. J. Health Popul. Nutr. 25, 465-468

Schade, R., and Hlinak, A. (1996). Egg yolk antibodies, state of the art and future prospects. Altex 13, 5-9.

Schade, R., Calzado, E. G., Sarmiento, R., Chacana, P. A., Porankiewicz-Asplund, J. and Terzolo, H. R. (2005).Chicken egg yolk antibodies (IgYtechnology):a review of progress in production and use in research and human and veterinary medicine. Altern. Lab. Anim. 33, 129-154.

Schmid-Hempel, R., and Schmid-Hempel, P. (1998). Colony performance and immunocompetence of a social insect, Bombusterrestris, in poor and variable environments. Funct. Ecol. 12, 22-30. doi: 10.1046/j.1365-2435.1998. 00153.x

Sentila, R., Karthika, S., Michael, A., and Gandhimathi, A. (2013). Protection against dental carries by passive immunization with hen egg yolk antibody using cell associated glucosyltransferase of Streptococcus mutans. J. Med. Microbiol. Diagnos 2:125. doi: 10.4172/2161-0703.1000125

Shen, K.F., Cao, L.-F., Cao, L., Ren, Q., Tan, F.-M., and Zhang, Y. (2017). Prevalence of sacbrood virus and treatment of its infection. Chin. J. Biol. 30, 954-957. 
Shimizu, M., Nagashima, H., Hashimoto, K., and Suzuki, T. (1994). Egg yolk antibody(IgY)stability in aqueous solution with high sugar concentrations. J. Food Sci. 59, 763-765. doi: 10.1111/j.1365-2621.1994.tb08122.x

Shimizu, M., Nagashima, H., Sano, K., and Hashimoto, K. (1993). Comparative studies on molecular stability of immunoglobulin $\mathrm{G}$ from different species. Comp .Biochem. Physiol, 106, 255-261. doi: 10.1016/0305-0491(93)90297-I

Sotiropoulou, G., Pampalakis, G., Prosnikli, E., Evangelatos, G. P., and Livaniou, E. (2012). Development and immunochemical evaluation of a novel chicken IgY antibody specific for KLK6. Chem. Central J. 6, 1-8. doi: 10.1186/1752-153X6-148

Sun, L., Li, M., Fei, D., Hu, Y., and Ma, M. (2017). Chinese sacbrood virus infection in Apismellifera, shandong, China, 2016, Virus Res. 242, 96-99. doi: 10.1016/j. virusres.2017.09.014

Tsevegmid, K., Neumann, P., and Yañez, O. (2016). The honey bee pathosphere of mongolia: european viruses in central asia. PLoS One 11:e0151164. doi: 10.1371/journal.pone.0151164

Vega, C. G., Bok, M., Vlasova, A. N., Chattha, K. S., Fernández, F. M., and Wigdorovitz, A. (2012). IgY antibodies protect against human Rotavirus induced diarrhea in the neonatal gnotobiotic piglet disease model. PLoS One 7:e42788. doi: 1 0.1371/journal.pone.0042788 doi: 10.1371/journal.pone. 0042788

Yan, X., and Han, R. C. (2008). Diagnostic technologies of common pathogens of honeybees in China. Chin. Bullet. Entomol. 45, 483-488.
Yong, L., Youliang, X., and Wenping, L. (2006). The preparation of oral IgY against and application in procambarus clarkia. J. Aquan. 27, 1-3.

Zhang, D. (2012). Research analysis bee of cystic larval disease occurrence in liaoning province. Chin. Indus .63, 19-20.

Zhang, J., Zhang, Y., and Han, R. (2016).The high-throughput production of dsRNA against sacbrood virus for use in the honey bee Apiscerana (Hymenoptera:Apidae). Virus Genes 52, 698-705 doi: 10.1007/s11262-0161346-6

Zhang, Y., Zhang, G., Huang, X., and Han, R. (2014). Proteomic analysis of Apiscerana and Apis mellifera larvae fed with heterospecific royal jelly and by CSBV challenge. PLoS One9:e102663. doi: 10.1371/journal.pone.0102663

Conflict of Interest Statement: The authors declare that the research was conducted in the absence of any commercial or financial relationships that could be construed as a potential conflict of interest.

Copyright (c) 2018 Sun, Li, Fei, Diao, Wang, Li and Ma. This is an open-access article distributed under the terms of the Creative Commons Attribution License (CC BY). The use, distribution or reproduction in other forums is permitted, provided the original author(s) and the copyright owner(s) are credited and that the original publication in this journal is cited, in accordance with accepted academic practice. No use, distribution or reproduction is permitted which does not comply with these terms. 